\title{
UV Photolysis Digestion Method for the Multielemental (Major to Ultratrace) Analysis of Liquid-based Dietary Supplements by ICP-MS and ICP-OES
}

\author{
M.V. Balarama Krishna*, G. Venkateswarlu, A.K. Sanjukta, and D. Karunasagar \\ National Center for Compositional Characterization of Materials (CCCM) \\ *Analytical Chemistry Division, Bhabha Atomic Research Centre \\ Department of Atomic Energy, Hyderabad - 500 062, India
}

\begin{abstract}
A UV photolysis digestion (UVPD) method using a mixture of $\mathrm{HNO}_{3}$ and $\mathrm{H}_{2} \mathrm{O}_{2}$ was developed for the determination of major, minor, and trace elements in dietary supplements (ethanolic extracts, liquid phytocaps, and syrups) as a possible alternative to conventional digestion methods. Optimization of the procedure involves the initial reaction with dilute nitric acid, followed by UVPD to yield a clear, colorless solution. Parameters affecting the UVPD method, such as acid concentration, amount of $\mathrm{H}_{2} \mathrm{O}_{2}$, digestion time and sample weight, were optimized to obtain the quantitative recovery ( $>95 \%$ ) of the analytes. The extent of
\end{abstract}

\section{INTRODUCTION}

Herbs and medicinal plants have been used for treating various diseases for a long time because of their beneficial properties for health (1). Since our lifestyles have become increasingly busy and leave less time to prepare well-balanced meals, our diets are at an increased risk of becoming nutrient-deficient. Dietary supplements sold as capsules, liquids, or in syrup form offer a simple and convenient way to supplement our diets and reduce the risk of nutrient deficiency.

Many people believe that products labeled "natural" are safe and good for them. This is not necessarily true because the safety of a botanical depends on many things,

*Corresponding autbor's E-mail: mvbalaramakrishna@rediffmail.com mineralization was determined on the basis of total organic carbon (TOC) measurement of the sample digests. Total digestion of the sample (i.e., complete colorless solution) can be achieved within 20-40 minutes of UV exposure time for a 300-mg sample. The clear sample solution obtained after UV photolysis digestion was used for the determination of $\mathrm{Na}, \mathrm{K}, \mathrm{Ca}, \mathrm{Mg}, \mathrm{Fe}, \mathrm{P}$, $\mathrm{Si}, \mathrm{Al}, \mathrm{Cr}, \mathrm{Mn}, \mathrm{Cu}$, and $\mathrm{Zn}$ using inductively coupled plasma optical emission spectrometry (ICPOES), while for the quantification of the elements $\mathrm{Co}, \mathrm{Ni}, \mathrm{Cu}, \mathrm{Zn}$, As, $\mathrm{Se}, \mathrm{Sr}, \mathrm{Tl}, \mathrm{Cd}, \mathrm{Cs}, \mathrm{Mo}, \mathrm{Hg}, \mathrm{Pb}$, and $\mathrm{Bi}$, inductively coupled plasma mass spectrometry (ICPMS) was used.

such as its chemical composition, how it functions in the body, how it is prepared, and the dosage. The majority of people taking supplements combine them with conventional drugs, which opens the possibility of herb-drug interactions, such as allergic and toxic reactions (2-5). Some herbs can also be hepatoxic (6).

Although organic components with medicinal properties often form the bulk of the supplement, dietary supplements also contain significant quantities of metals due to their ubiquitous nature. Several other possibilities exist to explain the presence of metals in dietary supplements. First, heavy metals may be added intentionally for their alleged medicinal properties, as done in the case of Indian Ayurvedic and traditional Chinese medicines. Secondly, the metals may be introduced as contaminants during vari- ous stages of manufacturing processes, such as grinding. Thirdly, raw materials may accumulate some metals from polluted soil or they may absorb metals present in the environment due to various anthropogenic and agricultural practices. It has been reported that some plants can accumulate up to $10 \%$ of the metals present in the soil (7).

More recently, Krishna et al. (8) have carried out arsenic speciation studies in ethanolic kelp and bladderwrack extracts by liquid chromatography particle beam electron ionization mass spectrometry (LC/PB-EI-MS). These investigations revealed that the majority (90-95\%) of the total arsenic content $\left(\sim 7 \mu \mathrm{g} \mathrm{g}^{-1}\right)$ in the samples is in the form of inorganic arsenic, with minor amounts of dimethyl arsenic acid (DMA).

Hence, the determination of metals in dietary supplements is of importance for nutritional and toxicological reasons. Previous studies of dietary supplements indicate that fairly high concentrations of these elements may occur $(2,3)$.

The number of dietary supplement samples submitted for trace elemental analysis is continuously growing. Hence, the demand for rapid, simple, and efficient analytical methods for the determination of the elemental composition in different types of dietary supplement sample matrices is increasing.

Several analytical techniques have been widely used for determining elemental composition data in various dietary supplement matrices which include atomic absorption spectrometry (AAS) 
$(9,10)$, inductively coupled plasma optical emission spectrometry (ICPOES) (11-14), inductively coupled plasma mass spectrometry (ICP-MS) (15-17), and anodic stripping voltammetry (ASV) (18). One of the most powerful analytical techniques for trace and ultratrace elemental analysis is ICP-MS due to its simultaneous multi-elemental detection capabilities, speed of analysis, and low detection limits (19-20).

The determination of the elemental composition in complex matrices such as food (in this case, botanical dietary supplements) often requires extensive sample preparation prior to instrumental analysis. Sample digestion methods for various matrices are largely limited to the conventional techniques of aqueous digestion based on an acid digestion with a heated mixture of mineral acids (21), dry ashing using a muffle furnace at around $500{ }^{\circ} \mathrm{C}$, fusion techniques, hot plate heating at $\sim 75^{\circ} \mathrm{C}(9,15$, 22), and microwave digestion. But most of these conventional digestion procedures are limited by several primary factors: long dissolution times (hours to days), potential loss of volatile elements, contamination of the sample through large quantities of reagents, and generally require a great deal of operator attention, skill, and experience in order to obtain accurate and precise results.

Very few methods have been reported in the literature for the mineralization of liquid-based dietary supplements, including ethanolic tinctures, liquid phytocaps, and syrups. More recently, Castro et al. (14) published a microwave digestion method suitable for multiple matrices (i.e., ethanolic tinctures, raw material, tablets and/or powders). Analytical chemists continue to search for sample preparation procedures that are faster, easier, and less expensive to perform, yet provide accu- rate and precise data with reasonable quantitation limits.

It is well-established that ICP-MS is a highly powerful and sensitive technique for pure aqueous solutions. Introduction of organic solvents into plasmas tend to cause complications due to cooling of the plasma and deposition of carbon on the cones which leads to a continuous variation in the signal. When the solvent content increases, it can lead to impedance mismatch thus extinguishing the plasma. These problems may be avoided sometimes by introducing a measured flow rate of oxygen into the argon carrier gas. In the absence of the provision to introduce oxygen, the organic solvent content must be kept to a minimum as possible. Hence, it is necessary to destroy the organic matrix before introducing the sample solution into the plasma.

An alternative to intensive sample preparation (usually requiring long periods of time, high temperatures, large quantities of concentrated acids, and tedious procedures) is oxidative UV photolysis with the use of a photodigestor equipped with a high-pressure mercury lamp. UV photolysis digestion is not based on direct interaction between UV radiation and the organic matrix, but rather involves the formation of many intermediate species such as the excited states of hydrogen peroxide, hydroxyl radicals, singlet oxygen, super-oxide ions, and radicals (23). However, the decomposition of organic matter requires the addition of substances such as $\mathrm{HNO}_{3}$ and $\mathrm{H}_{2} \mathrm{O}_{2}$ which facilitate the UV oxidation process.

The oxidation of organic matter and freeing of organic-bound metals and non-metals in water matrices under the influence of UV radiation was initially described by Armstrong et al. (24) as an efficient sample preparation method. Since its introduction, UV photo-oxidation has been effectively used for the decomposition of organic phosphates in waters and detergents (25), the determination of total nitrogen and phosphorus by spectrophotometry, trace element determination and speciation by atomic spectrometry, (26), and the determination of trace metals by voltammetry (27). The UV-assisted digestion method has also been utilized for the ion chromatographic and voltammetric determinations of heavy and transition metals in honey and the destruction and mineralization of organic compounds in urine (28). Recently, Manjusha et al. (29) developed a UV oxidation procedure to completely digest biological and food-related samples for the determination of selenium at trace levels. But to our knowledge, no study has yet been reported on the UV-assisted digestion of liquidbased dietary samples of botanical origin - until now.

The objective of this study was to determine the levels of various elements (major to ultratrace) in three diverse and widely used dietary supplements: ethanolic extracts, liquid phytocaps, and syrups. It is well known that not only is the determination of element concentrations in these supplements very important, but also a reliable analytical procedure for sample preparation is a critical step. In this work, the capability of the UV photolysis digestion method for the quantitative determination of major to ultratrace elements using a mixture of $\mathrm{HNO}_{3}$ and $\mathrm{H}_{2} \mathrm{O}_{2}$ was evaluated for the analysis of these types of dietary supplement samples.

\section{EXPERIMENTAL}

\section{Instrumentation}

The determination of elements in the samples after extraction was carried out using a VG PQ ExCell inductively coupled plasma mass spectrometer (ICP-MS) (VG Elemen- 
tal, Winsford, Cheshire, U.K), located in a class 10,000 area. The system is equipped with a Meinhard $\AA$ concentric nebulizer and an impact bead Peltier-cooled spray chamber. The ion lens voltage settings and other parameters of the instrument were tuned every day, employing a 10 -ng $\mathrm{mL}^{-1}$ solution containing $\mathrm{Li}, \mathrm{Be}, \mathrm{Ba}, \mathrm{Ce}, \mathrm{Co}$, $\mathrm{In}, \mathrm{Pb}, \mathrm{Bi}$, and $\mathrm{U} .{ }^{103} \mathrm{Rh}$ was used as an internal standard for all determinations to correct for instrumental drift and matrix effects, if any.

Determination of the major elements $\mathrm{Al}, \mathrm{Pb}, \mathrm{Na}, \mathrm{K}, \mathrm{Ca}, \mathrm{Mg}, \mathrm{Fe}, \mathrm{P}$, and $\mathrm{Si}$ was carried out by inductively coupled plasma optical emission spectrometry (ICP-OES) (JY-2000, France), whereas the determination of $\mathrm{Zn}, \mathrm{Mn}$, and $\mathrm{Cu}$ was carried out by both ICP-MS and ICP-OES. The optimized parameters of both ICP-MS and ICP-OES are given in Tables Ia and $\mathrm{Ib}$, respectively.

Before ICP-MS and ICP-OES analysis, test dietary samples were subjected to UV photolysis in a UV digestor (Model No. 705, Metrohm, Herisau, Switzerland), equipped with a high-pressure $500 \mathrm{~W}$ mercury lamp. The $705 \mathrm{UV}$ digester is comprised of a sample holder for 12 quartz tubes (15-mL capacity) with fitted Teflon ${ }^{\circledR}$ conical caps. For each set of samples, one quartz tube was reserved for the thermometer that was utilized for monitoring the digestion temperature. The temperature for each digestion under optimal digestion conditions was maintained at $85 \pm 5^{\circ} \mathrm{C}$ with the help of the water-cooling system connected to the digester.

Total digestion was carried out using a microwave digestion system (CEM Corporation, Mars 5 Express, Mathews, NC, USA). The total organic carbon (TOC) content of the samples before and after UV photolysis was determined with a TOC analyzer (ANATOC II series, SGE, Australia).

\section{Reagents and Materials}

Sub-boiled $\mathrm{HCl}$ and $\mathrm{HNO}_{3}$ were prepared by sub-boiling distillation in quartz stills. Ultra-pure water with $>18 \mathrm{M} \Omega$ resistivity, obtained using a Milli- $\mathrm{Q}^{\mathrm{TM}}$ high purity water system located in a class 200 area, was used for dilution of the standards, preparing the samples, and final rinsing of the acid-cleaned vessels. Hydrogen peroxide of Suprapur ${ }^{\circledR}$ grade (E. Merck, Darmstadt, Germany) was used during the UV

\section{Atomic Mpectroscopy \\ $\bigcup$ Vol. 32(4), July/August 2011}

digestion process. All containers were cleaned in $20 \% \mathrm{HNO}_{3}$ prior to use. Multi-element standard solutions $\left(1000 \mu \mathrm{g} \mathrm{mL}{ }^{-1}\right.$, CertiPUR ${ }^{\circledR}$ reference material, E. Merck, Darmstadt, Germany) were used in the preparation of the working standards by sequential dilutions for ICP-MS and ICP-OES analysis. Sets of mixed working standard solutions, each consisting of four or five concentration levels $(2.5,5,10$, 50 , and $100 \mathrm{ng} \mathrm{mL}^{-1}$ ) with $\mathrm{Rh}$ as the internal standard $\left(25 \mathrm{ng} \mathrm{mL}^{-1}\right)$ were

TABLE I (a)

ICP-MS Instrumental and Operating Parameters

\begin{tabular}{|c|c|c|}
\hline \multicolumn{2}{|c|}{ Instrumental Parameters } & Scanning Parameters \\
\hline Coolant gas & $13.4 \mathrm{~L} \mathrm{~min}^{-1}$ & Scanning mode \\
\hline Auxiliary gas & $0.88 \mathrm{~L} \mathrm{~min}^{-1}$ & Number of replicates \\
\hline Nebulizer gas & $1.06 \mathrm{~L} \mathrm{~min}^{-1}$ & 100 millisec/channel \\
\hline Sampler cone & $1.0 \mathrm{~mm} \mathrm{Ni}$ & Sample uptake time $\quad 50 \mathrm{sec}$ \\
\hline Skimmer cone & $0.7 \mathrm{~mm} \mathrm{Ni}$ & Washing time \\
\hline Torch type & Fassel & Sample uptake rate \\
\hline Plasma FW power & $1300 \mathrm{~W}$ & $\mathrm{~m} / \mathrm{z}^{53} \mathrm{Cr},{ }^{55} \mathrm{Mn}$ \\
\hline Reflected power & $<0.8 \mathrm{~W}$ & $\begin{array}{l}{ }^{65} \mathrm{Cu},{ }^{60} \mathrm{Ni},{ }^{66} \mathrm{Zn},{ }^{75} \mathrm{As},{ }^{78} \mathrm{Se},{ }^{88} \mathrm{Sr},{ }^{95} \mathrm{Mo}, \\
{ }^{112} \mathrm{Cd},{ }^{137} \mathrm{Ba},{ }^{205} \mathrm{Tl},{ }^{202} \mathrm{Hg},{ }^{208} \mathrm{~Pb} \text {, and } \\
{ }^{209} \mathrm{Bi}\end{array}$ \\
\hline
\end{tabular}

TABLE I (b)

ICP-OES Instrumental and Operating Conditions (Jobin Yvon JY 2000)

\begin{tabular}{|c|c|c|c|c|}
\hline \multicolumn{2}{|c|}{ Parameters Use } & \multicolumn{3}{|c|}{ Operating Conditions } \\
\hline \multicolumn{2}{|c|}{ Plasma gas flow rate } & \multicolumn{3}{|c|}{$12 \mathrm{~L} \mathrm{~min}^{-1}$} \\
\hline \multicolumn{2}{|c|}{ Sheath gas flow rate } & \multicolumn{3}{|c|}{$0.2 \mathrm{~L} \mathrm{~min}^{-1}$} \\
\hline \multicolumn{2}{|c|}{ Sample uptake rate } & \multicolumn{3}{|c|}{$1.0 \mathrm{~mL} \mathrm{~min}^{-1}$} \\
\hline \multicolumn{2}{|l|}{ RF Generator } & \multicolumn{3}{|c|}{$1000 \mathrm{~W}$, Frequency $40.68 \mathrm{MHz}$} \\
\hline \multicolumn{2}{|c|}{ Monochromator } & \multicolumn{3}{|c|}{$\begin{array}{l}0.64 \mathrm{M}, 2400 \text { lines } / \mathrm{mm} \text {, } \\
\text { Czerny Turner mounting }\end{array}$} \\
\hline \multicolumn{2}{|l|}{ Torch } & \multicolumn{3}{|c|}{$\begin{array}{l}\text { Jobin Yvon demountable quartz with } \\
\text { argon sheathing gas }\end{array}$} \\
\hline \multicolumn{2}{|c|}{ R. F. Forward power } & \multicolumn{3}{|c|}{$1.05 \mathrm{KW}(<10 \mathrm{~W}$ reflected power) } \\
\hline Element & \multicolumn{2}{|c|}{ Wavelength (nm) } & Element & Wavelength (nm) \\
\hline $\mathrm{Zn}$ & \multicolumn{2}{|c|}{213.856} & $\mathrm{Mg}$ & 279.553 \\
\hline $\mathrm{P}$ & \multicolumn{2}{|c|}{214.914} & $\mathrm{Cu}$ & 324.754 \\
\hline $\mathrm{Fe}$ & \multicolumn{2}{|c|}{238.204} & $\mathrm{Ca}$ & 393.367 \\
\hline $\mathrm{Si}$ & \multicolumn{2}{|c|}{251.611} & $\mathrm{Al}$ & 396.152 \\
\hline \multirow[t]{2}{*}{$\mathrm{Mn}$} & \multirow{2}{*}{\multicolumn{2}{|c|}{257.610}} & $\mathrm{Na}$ & 589.592 \\
\hline & & & $\mathrm{K}$ & 766.490 \\
\hline
\end{tabular}


employed for calibration of the ICPMS. Similarly, another set of mixed working standard solutions ranging from 100 to $3000 \mathrm{ng} \mathrm{mL}^{-1}$ (Al, Cu, $\mathrm{Zn}, \mathrm{Mn}, \mathrm{Na}, \mathrm{Ca}, \mathrm{K}, \mathrm{Mg}, \mathrm{Si}$, and $\mathrm{P}$ ) was used for calibrating the ICP-OES.

Dietary supplements of the following three different matrices were used in this study and provided by GAIA Herbs (Brevard, NC, USA): ethanolic tinctures (consisting of 20 to $65 \%$ ethanol), liquid phytocaps (40-60\% glycerin), and syrups.

\section{UV Photolysis Digestion Procedure (UVPD)}

For optimization of the UVPD procedure, an ethanolic extract of green tea, ginger phytocap, and syrup for bronchial wellness were chosen as representatives of the three diverse matrices: ethanolic tinctures, liquid-phytocaps, and syrups, respectively.

Accurately weighed amounts (0.3-0.5 g) of different aliquots of these representative dietary samples were placed into pre-cleaned 25-mL glass beakers containing $5 \mathrm{~mL}$ of $20 \% \mathrm{HNO}_{3}$ solution. The sample mixtures were gently heated on an IR heater (Schott Instruments, Germany) to prevent foaming. This treatment was continued until the reaction was complete (i.e., until no effervescence seen). After this pre-digestion treatment, the sample solutions were transferred into a 12-mL quartz vial, $200 \mu \mathrm{L}$ of $\mathrm{H}_{2} \mathrm{O}_{2}(30 \%)$ was added, and the sample subjected to UV photolysis, while maintaining the sample temperature at $80-85^{\circ} \mathrm{C}$. During the digestion period of 20-40 minutes, at each 10-minute interval, a 100- $\mu \mathrm{L}$ aliquot of $\mathrm{H}_{2} \mathrm{O}_{2}$ was added. This addition process aims at ensuring that the oxidizing conditions are maintained throughout the UV-assisted digestion process. The samples were exposed to UV light until clear and colorless solutions were obtained. At the end of the digestion, the samples were made up to the required volume with high-purity water for analysis by ICP-MS and/or ICP-OES.

Corresponding process blanks were also prepared in the same way without any sample material. Three aliquots of each sample were used for each UVPD procedure. With each series of digestions, a blank was also measured. All of the analytical measurements were run in triplicate for the sample solutions. Calculations of the metal content in the samples are based on calibration plots obtained from aqueous standards. Upon the development of the UVPD procedure, the results were compared with those obtained with the recently published microwave digestion procedure without any further modifications.

\section{RESULTS AND DISCUSSION}

The different types of dietary samples used in the present work and their main medicinal properties are listed in Table II.

\section{Development of UV Photolysis Digestion (UVPD) Procedure}

Initially, UVPD was applied directly to the dietary samples wherein concentrated $\mathrm{HNO}_{3}$ was added to the quartz vial containing a weighed aliquot of the test sample. But due to the violent reaction of $\mathrm{HNO}_{3}$ with liquid dietary extracts (in particular, ethanolbased extracts which produce nitrogen dioxide gases), this direct UVPD approach was not successful for dietary samples that contain different percentages of alcohol/ glycerin. To some extent, this procedure was partially successful for the ethanol-based samples. Based on these preliminary studies, this direct UVPD procedure had several disadvantages, including incomplete recovery of the analytes due to splashing, loss of analytes, and the time-consuming ( $>1 \mathrm{hr}$ ) nature of the digestion. To overcome these limitations, a pre-digestion hot plate step was introduced before applying UVPD. The sample volume of $5 \mathrm{~mL}$ was kept constant in all of the optimization studies.

\section{Optimization of Pre-digestion Step}

A pre-digestion step is generally beneficial especially for samples rich in organic content. In this work, pre-digestion was performed by gently heating the sample and acid on an IR hot plate. One method of avoiding the violent reaction of nitric acid with alcohol-based extracts is to predigest the sample by heating it gently $\left(70-80^{\circ} \mathrm{C}\right)$ on an IR hot plate after the addition of $5 \mathrm{~mL}$ of $20 \%$ nitric acid, This enables the gases (evolving from the decomposition of easily oxidized organic matter) to escape before commencing the UVPD procedure.

\section{Acid Concentration}

Acid treatment of a sample matrix is governed by many complex relationships such as solubility and oxidizing power of the acid to liberate the trace elements. The acid, or a combination of acids, is chosen for its efficiency in decomposing the matrix. It is usually desirable for the acid to form a soluble salt with the metal ion of interest. For these reasons, nitric acid, hydrochloric acid, and perchloric acid are widely used in sample preparations.

Among the acids employed, $\mathrm{HNO}_{3}$ is reported to have an enhanced performance for oxidation of the organic matter due to its strong oxidizing properties. Hence, nitric acid is a widely used oxidizing agent for liberating trace elements from biological and botanical matrices as highly soluble nitrate salts. However, decomposition of the organic media also requires the addition of $\mathrm{H}_{2} \mathrm{O}_{2}$ to facilitate the oxidation process. 


\section{A Aomic}

TABLE II

List of Dietary Supplements Used for the Determination of Elemental Composition

\begin{tabular}{|c|c|c|c|c|}
\hline S. No. & Supplement Name & Medium & Medicinal Uses & Suggested Daily Dosage \\
\hline 1 & $\begin{array}{l}\text { Bladderwrack Fronds } \\
\text { (Fucus vesiculosus) }\end{array}$ & $\begin{array}{l}\text { Spring water }+20-30 \% \\
\text { pure grain alcohol }\end{array}$ & $\begin{array}{l}\text { To treat arteriosclerosis } \\
\text { and iodine-deficiency } \\
\text { ailments }\end{array}$ & $\begin{array}{l}30-40 \text { drops in water, } \\
3-4 \text { times }\end{array}$ \\
\hline 2 & Echinacea supreme & $\begin{array}{l}\text { Water }+50-60 \% \text { organic } \\
\text { grain alcohol }\end{array}$ & $\begin{array}{l}\text { Ultimate support for health } \\
\text { human function }\end{array}$ & $\begin{array}{l}40-60 \text { drops in water, } \\
4-6 \text { times }\end{array}$ \\
\hline 3 & $\begin{array}{l}\text { Green Tea } \\
\text { (Camellia sinensis) }\end{array}$ & $\begin{array}{l}\text { Water }+35-45 \% \text { organic } \\
\text { grain alcohol }\end{array}$ & $\begin{array}{l}\text { Strong source of polyphenols } \\
\text { which have strong anti- } \\
\text { oxidant, anti-carcinogenic } \\
\text { and anti-arthritic properties }\end{array}$ & $\begin{array}{l}30-40 \text { drops in water, } \\
3-4 \text { times }\end{array}$ \\
\hline 4 & Milk thistle seed & $\begin{array}{l}\text { Water }+35-45 \% \text { organic } \\
\text { grain alcohol }\end{array}$ & $\begin{array}{l}\text { Ultimate support for healthy } \\
\text { liver function }\end{array}$ & $\begin{array}{l}30-40 \text { drops in water, } \\
3-4 \text { times }\end{array}$ \\
\hline 5 & $\begin{array}{l}\text { Olive leaf } \\
\text { (Olea europaea) }\end{array}$ & $\begin{array}{l}\text { Water }+55-65 \% \text { organic } \\
\text { grain alcohol }\end{array}$ & $\begin{array}{l}\text { Protects the body from } \\
\text { viruses, bacteria or retro- } \\
\text { viruses, possible Anti HIV } \\
\text { activity, etc. }\end{array}$ & $\begin{array}{l}30-40 \text { drops in water, } \\
3-4 \text { times }\end{array}$ \\
\hline 6 & Nicotine Relief & $\begin{array}{l}\text { Spring water }+50-60 \% \\
\text { grain alcohol }\end{array}$ & $\begin{array}{l}\text { Supports healthy response } \\
\text { to environmental stresses }\end{array}$ & $\begin{array}{l}15-20 \text { drops in warm } \\
\text { water, } 3 \text { times }\end{array}$ \\
\hline 7 & $\begin{array}{l}\text { Daily Bitters } \\
\text { (alcohol-free) }\end{array}$ & $\begin{array}{l}\text { Water and } 60 \% \\
\text { vegetable glycerin }\end{array}$ & $\begin{array}{l}\text { Supports healthy digestion, } \\
\text { absorption and elimination }\end{array}$ & $\begin{array}{l}45 \text { drops in water, } \\
\text { twice daily }\end{array}$ \\
\hline 8 & Echinacea supreme & $\begin{array}{l}\text { Water and } 60 \% \\
\text { vegetable glycerin }\end{array}$ & $\begin{array}{l}\text { Ultimate support for healthy } \\
\text { immune function }\end{array}$ & $\begin{array}{l}30-50 \text { drops in water, } \\
4-5 \text { times }\end{array}$ \\
\hline 9 & $\begin{array}{l}\text { Ginkgo leaf } \\
(\text { Ginkgo biloba) }\end{array}$ & $\begin{array}{l}\text { Spring water and } \\
50-60 \% \text { glycerin }\end{array}$ & $\begin{array}{l}\text { Promotes memory and } \\
\text { circulation }\end{array}$ & $\begin{array}{l}30-40 \text { drops in warm } \\
\text { water, } 3-4 \text { times }\end{array}$ \\
\hline 10 & Anti-oxidant supreme & $\begin{array}{l}\text { Alcohol-free concentrated } \\
\text { extract }\end{array}$ & Whole body support & 1 capsule, 2 times \\
\hline 11 & Black Elderberry & $\begin{array}{l}\text { Alcohol free concentrated } \\
\text { extract }\end{array}$ & Healthy immune function & 2 capsules, 2 times \\
\hline 12 & Echinacea supreme & $\begin{array}{l}\text { Alcohol-free concentrated } \\
\text { extract }\end{array}$ & Healthy immune function & $\begin{array}{l}2 \text { capsules with warm } \\
\text { water, every } 2 \text { hours }\end{array}$ \\
\hline 13 & Green tea & $\begin{array}{l}\text { Alcohol-free concentrated } \\
\text { extract }\end{array}$ & $\begin{array}{l}\text { Rich in naturally occurring } \\
\text { anti-oxidants }\end{array}$ & 2 capsules, 2 times \\
\hline 14 & Olive leaf & $\begin{array}{l}\text { Alcohol-free concentrated } \\
\text { extract }\end{array}$ & Healthy immune function & 1 capsule, 2 times \\
\hline 15 & Ginger supreme & $\begin{array}{l}\text { Alcohol-free concentrated } \\
\text { extract }\end{array}$ & $\begin{array}{l}\text { Supports a healthy inflam- } \\
\text { matory response }\end{array}$ & 1 capsule, $1-2$ times \\
\hline 16 & Ginkgo leaf & $\begin{array}{l}\text { Alcohol-free concentrated } \\
\text { extract }\end{array}$ & $\begin{array}{l}\text { Promotes healthy circulation } \\
\text { and memory }\end{array}$ & 1 capsule, 2 times \\
\hline 17 & Kava-kava root & $\begin{array}{l}\text { Alcohol-free concentrated } \\
\text { extract }\end{array}$ & $\begin{array}{l}\text { Restores calm and } \\
\text { relaxation }\end{array}$ & 1 capsule, 3 times \\
\hline 18 & Turmeric supreme & $\begin{array}{l}\text { Alcohol-free concentrated } \\
\text { extract }\end{array}$ & $\begin{array}{l}\text { Supports heart, joint and } \\
\text { liver function }\end{array}$ & 1 capsule, $1-2$ times \\
\hline 19 & Bronchial Wellness & Herbal syrup & $\begin{array}{l}\text { Promotes well-being of the } \\
\text { respiratory tract by supporting } \\
\text { bronchial health }\end{array}$ & $10 \mathrm{~mL}$, twice daily \\
\hline 20 & Black Elderberry & Syrup & $\begin{array}{l}\text { Flavonoid compounds are } \\
\text { directly responsible for many } \\
\text { health promoting properties }\end{array}$ & $10 \mathrm{~mL}$, twice daily \\
\hline
\end{tabular}

S. No 7-18 are phyto-caps; 1 drop $=20-25 \mathrm{mg} ; 1$ capsule weighs $\sim 800-820 \mathrm{mg}$. 
In view of these excellent properties, a mixture of $\mathrm{HNO} 3$ and $\mathrm{H}_{2} \mathrm{O}_{2}$ was selected for the present studies. As mentioned previously, the reaction of $\mathrm{HNO}_{3}$ with ethanol is very violent; hence, concentrated $\mathrm{HNO}_{3}$ could not be used. Therefore, the concentration of $\mathrm{HNO}_{3}$ required for a reaction to occur was varied from 10 to $50 \%(\mathrm{v} / \mathrm{v})$. These experiments clearly indicate that pre-digestion time is directly proportional to the amount of $\mathrm{HNO}_{3}$ that is being used. But the reaction turns violent if the acid concentration is more than $40 \%$. The lower recoveries experienced at $>40 \%$ can therefore be explained by loss of sample due to an overflowing of the sample during heating. As a tradeoff between pre-digestion time and amount of acid, the concentration of $\mathrm{HNO}_{3}$ was fixed at 20\% for the reaction to complete in less than 5 minutes.

With the aim of improving predigestion conditions for the maximum number of elements, the following acid mixtures were also investigated: $\mathrm{HNO}_{3}(10 \%)+\mathrm{HCl}$ (10\%), $\mathrm{HNO}_{3}(20 \%)+\mathrm{HCl}(10 \%)$, and $\mathrm{HNO}_{3}(10 \%)+\mathrm{HCl}(20 \%)$ (V/V). No significant improvement in the reaction conditions of the pre-digestion step was observed with any of these acid mixtures. Hence, $20 \% \mathrm{HNO}_{3}$ alone was used for pre-digestion in the subsequent experiments.

About $300 \mathrm{mg}$ of the dietary sample was weighed into a $25-\mathrm{mL}$ glass beaker containing $5 \mathrm{~mL}$ of $20 \%$ $\mathrm{HNO}_{3}$. Then, the sample mixture was heated gently to around $80^{\circ} \mathrm{C}$ until the reaction was complete. It was observed that the total predigestion time with a 300-mg sample and $5 \mathrm{~mL} 20 \% \mathrm{HNO}_{3}$ was about 3 minutes. After the pre-digestion step, the sample mixture was transferred quantitatively into a $12-\mathrm{mL}$ quartz vial for carrying out the UVPD procedure. Corresponding blanks were prepared in the same way without any sample material.

\section{UV Photolysis System Optimization}

To assess the ability of the UV photolysis system to digest the various dietary supplements in the present work, a study was conducted for the optimization of various parameters, including digestion time (15-45 minutes), temperature $\left(70-95^{\circ} \mathrm{C}\right)$, and the amount of sample (100-500 mg). The optimized concentration of $20 \% \mathrm{HNO}_{3}$ was used for all optimization studies.

\section{Digestion Time}

The time necessary to achieve total digestion depends on temperature and amount of sample used for digestion. In the present study, the digestion time was varied between 5 and 45 minutes with 10-minute intervals and maintaining a constant temperature of the UV system $\left(\sim 85^{\circ} \mathrm{C}\right)$, acid concentration $(20 \%$ $\left.\mathrm{HNO}_{3}, \mathrm{v} / \mathrm{v}\right)$, and sample weight (300 mg). In all cases, the digestion efficiency of the UVPD system increases with increasing UV exposure time. Clear and colorless digests were obtained in almost all cases within a digestion period of $30 \mathrm{~min}$ utes. But the digestion time varied from 15 to 45 minutes with different sample viscosities. These studies clearly indicate that the time required for complete digestion of the ethanolic extracts is about 10-15 minutes, while samples of more concentrated botanical material (such as glycerine-based phytocaps turmeric supreme and kava kava) needed more UV exposure time (up to 45 minutes).

The volume of $\mathrm{H}_{2} \mathrm{O}_{2}$ was also optimized by adding different amounts (between 100-400 $\mu \mathrm{L}$ ) during different intervals of UV exposure. During these optimization studies, it was observed that bumping or overflowing of the sample solution from the quartz vial occurs when the volume of $\mathrm{H}_{2} \mathrm{O}_{2}$ exceeds $300 \mu \mathrm{L}$ at each interval. This behavior is possibly due to the generation of high amounts of reac- tive $\mathrm{OH}$ radicals which react with the organic matrix upon UV irradiation, thereby resulting in the release of large amounts of gases such as $\mathrm{CO}_{2}, \mathrm{NO}_{2}$, and NO. Hence, the volume of $\mathrm{H}_{2} \mathrm{O}_{2}$ added at each interval of UV photolysis was fixed at $200 \mu \mathrm{L}$.

\section{Sample Temperature}

Experiments were carried out to examine the effect of sample temperature on digestion. Irradiation with a high wattage ( $500 \mathrm{~W}$ power, $\sim 10 \mathrm{MPa}$ pressure) mercury lamp results in high temperatures (up to $600{ }^{\circ} \mathrm{C}$ ), which must be controlled to avoid loss of analytes due to volatilization and/or overflowing of the sample due to the release of very high quantities of gases. Hence, the sample temperature was always maintained at about $85^{\circ} \mathrm{C}$ using a water-cooling system when UV irradiation experiments were performed to prevent the loss of sample.

\section{Sample Weight}

It has been reported that digestion time is directly proportional to UV intensity and irradiation time, while it is inversely proportional to the organic content of the sample matrix. In this work, the digestion of liquid-based dietary samples and quantitative recovery were investigated when different sample amounts $(0.1,0.2,0.3,0.4$, and $0.5 \mathrm{~g})$ were used for UV oxidation. UV exposure time, acid concentration (20\% $\left.\mathrm{HNO}_{3}\right)$, and sample temperature $\left(\sim 85^{\circ} \mathrm{C}\right)$ were kept constant during these studies. It was observed that complete digestion of the sample and quantitative recovery with good precision for most of the elements was achieved when the sample weight was $0.3 \mathrm{~g}$; this mass was used in all further studies of the present work.

\section{Analytical Response Character- istics of the Method}

Once optimization of the operating parameters of the UVPD proce- 
dure and the complete dissolution of the dietary samples were achieved, the analytical response characteristics were determined for each of the elements of interest using multi-element standard solutions. Five-point external calibrations with standards traceable to the National Institute of Standards and Technology (NIST, Gaithersburg, MD, USA) were used to quantify the elements after UV photolysis digestion. The calibration curves were generated for each element across a concentration range from 0 (i.e., analytical blank) to $100 \mathrm{ng} \mathrm{mL}^{-1}$ for the ICP-MS measurements and 0 to $5 \mu \mathrm{g} \mathrm{mL}^{-1}$ for ICP-OES. Good linearity and satisfactory correlation coefficients $\left(R^{2}>0.998\right)$ were obtained for each of the elemental response functions. According to IUPAC definition, the limits of detection (LOD) were calculated from each calibration response as the concentration of an analyte yielding a signal equivalent to three times the standard deviation (LOD $=3 \sigma$ ) of the blank value. The relative standard deviation (RSD) values were below $2 \%$ for the major elements and $<8 \%$ for all of the trace and ultratrace elements selected in the present study.

\section{Validation of UVPD Method}

Validation of the developed UVPD procedure is necessary to ensure the efficacy of the procedure to digest the samples, including the removal of organic matter in such a manner that quantitative recovery and an accurate determination of the elemental composition of the test dietary samples are obtained. Since there is a lack of suitable certified reference materials for liquidbased dietary supplements, the method validation was accomplished by digesting the same set of dietary samples using a recently reported microwave assisted digestion method (14).
In UV-photolysis, oxidizing free radicals are utilized for the oxidation of the organic matrix. But UV radiation can also induce photoreduction with some of the free radicals (such as $\mathrm{H}^{*}$ and $\mathrm{CO}^{\circ}$ ) that promote reduction instead of oxidation, thus giving rise to loss of certain analytes. Hence, it is necessary to carry out recovery studies of the analytes. Prior to carrying out the UVPD procedure for the selected dietary products, it was first carried out for the test elements present in neat aqueous standard solutions. The recovery values obtained for a mixture of the aqueous standards (20 $\mathrm{ng} \mathrm{mL}^{-1}$ for ICP-MS and $1 \mu \mathrm{gL}^{-1}$ for ICP-OES) after applying the UVPD procedure (as described in previous sections) followed by ICPMS and ICP-OES analysis are listed in the first column of Table III. Quantitative recoveries (>95\%) for each of the elements obtained with the optimized UVPD procedure demonstrated that there was no significant loss during the UV-photolysis process.

Validation of the UVPD procedure developed for the three different matrices (ethanolics, phytocaps, and syrups) was carried out using both external and standard addition calibrations which are the most common approaches for both ICPMS and ICP-OES measurements. For this evaluation, three different dietary samples (green tea ethanolic extract, ginger supreme phytocap, and black elderberry syrup taken as representatives for three sample matrix types), were spiked with a mixed standard solution containing each of the test elements prior to the UVPD process. The purpose of this study was to identify the matrix effect of different botanical products on the ICP analyses.

As seen in Table III, recoveries of $95 \%$ and higher were obtained for each of the test elements, with the exception of mercury, which gave a $65 \%$ recovery for aqueous standard solutions. The loss of mercury during the UVPD process could mainly be due to the volatility of the element with high power (500 W) UV irradiation, while the recovery of mercury was quantitative (>95\%) for the different sample matrices. In this case, UV radiation is mainly utilized for destroying/ decomposing organics causing less volatility of the mercury. More studies need to be performed to ascertain the loss of mercury.

Good agreement was also seen between the results obtained with both the external and standard addition procedures. This clearly demonstrates the capabilities of the UVPD method for destroying the organic matrix present in the dietary samples, thus eliminating significant spectral interferences during ICP-OES analysis. Because both the external and standard addition approaches provided good results, analysis of the different dietary extracts was carried out using only the external calibration method in all subsequent studies since a large number of dietary samples were analyzed.

The efficiency of the developed photolysis process of dietary extracts was evaluated by measuring the total organic carbon (TOC) content in three dietary samples (Olive Leaf Extract, Daily Bitters, and Ginkgo Leaf) before and after the complete UV photolysis process. The TOC content was also measured in the samples after applying microwave-assisted digestion for comparison; the results are presented in Table IV. It can be seen that there is a more than 100fold decrease in the percentage of TOC in all of the samples tested, demonstrating the ability of the UVPD procedure towards the mineralization of various dietary extracts. 
TABLE III

Elemental Recoveries (\%) for Aqueous Standard Solutions and Three Dietary

\begin{tabular}{|c|c|c|c|c|c|c|c|c|}
\hline Element & $\begin{array}{l}\text { Aqueous } \\
\text { ICP-MS }\end{array}$ & $\begin{array}{l}\text { standards } \\
\text { ICP-OES }\end{array}$ & $\begin{array}{c}\text { Green Tea E } \\
\text { ICP-MS }\end{array}$ & $\begin{array}{l}\text { hanolic Extract } \\
\text { ICP-OES }\end{array}$ & $\begin{array}{c}\text { Ginger Sup } \\
\text { ICP-MS }\end{array}$ & $\begin{array}{l}\text { ne Phytocap } \\
\text { ICP-OES }\end{array}$ & $\begin{array}{c}\text { Black Elde } \\
\text { ICP-MS }\end{array}$ & $\begin{array}{l}\text { berry Syrup } \\
\text { ICP-OES }\end{array}$ \\
\hline $\mathrm{Cr}$ & 96.0 & - & 96.0 & - & 96.0 & - & 95.0 & - \\
\hline Mn & 101.0 & 99.8 & 101.0 & 99.0 & 99.5 .0 & 98.0 & 103.0 & 101.0 \\
\hline $\mathrm{Ni}$ & 97.2 & - & 96.5 & - & 96.0 & - & 97.0 & - \\
\hline Co & 100.0 & - & 100.0 & - & 99.5 & - & 99.0 & - \\
\hline $\mathrm{Cu}$ & 99.0 & 101.0 & 99.0 & 99.5 & 98.0 & 99.0 & 97.0 & 100.0 \\
\hline $\mathrm{Zn}$ & 102.0 & 103.0 & 102.0 & 103.0 & 102.0 & 103.0 & 102.0 & 103.0 \\
\hline As & 96.0 & - & 95.0 & - & 95.5 & - & 96.2 & - \\
\hline $\mathrm{Se}$ & 95.2 & - & 95.5 & - & 95.0 & - & 96.0 & - \\
\hline Mo & 95.5 & - & 95.0 & - & 96.7 & - & 96.0 & - \\
\hline $\mathrm{Cd}$ & 99.6 & - & 99.0 & - & 98.0 & - & 99.4 & - \\
\hline Cs & 98.8 & - & 100.0 & - & 99.0 & - & 100.0 & - \\
\hline $\mathrm{Ba}$ & 98.0 & - & 97.0 & - & 98.5 & - & 98.0 & - \\
\hline $\mathrm{Hg}$ & 65.0 & - & 95.0 & - & 95.4 & - & 95.8 & - \\
\hline $\mathrm{Tl}$ & 96.0 & - & 97.0 & - & 96.0 & - & 99.0 & - \\
\hline $\mathrm{Pb}$ & 99.0 & - & 101.0 & - & 100.0 & - & 98.0 & - \\
\hline $\mathrm{Bi}$ & 98.0 & - & 98.0 & - & 99.0 & - & 100.0 & - \\
\hline $\mathrm{Al}$ & - & 97.0 & - & 96.0 & - & 97.0 & - & 98.0 \\
\hline $\mathrm{Fe}$ & - & 99.5 & - & 99.0 & - & 102.0 & - & 100.0 \\
\hline $\mathrm{Na}$ & - & 102.0 & - & 101.0 & - & 99.5 & - & 101.0 \\
\hline $\mathrm{K}$ & - & 99.5 & - & 101.0 & - & 99.0 & - & 99.4 \\
\hline $\mathrm{Ca}$ & - & 98.7 & - & 99.6 & - & 102.0 & - & 101.0 \\
\hline $\mathrm{Mg}$ & - & 99.0 & - & 98.9 & - & 99.2 & - & 99.5 \\
\hline $\mathrm{P}$ & - & 96.6 & - & 96.0 & - & 98.0 & - & 96.3 \\
\hline $\mathrm{Si}$ & - & 99.0 & - & 98.7 & - & 101.0 & - & 98.0 \\
\hline
\end{tabular}

TABLE IV

TOC Values Obtained for Some of the Dietary Samples Before and After Applying UVPD and Microwave Digestion

\begin{tabular}{cccc}
\hline Dietary Sample & Initial TOC & TOC Content After Digestion \\
\hline & & UVPD & $\begin{array}{c}\text { Microwave } \\
\text { Digestion }\end{array}$ \\
\hline Daily Bitters & $34 \%$ & $0.23 \%$ & $0.20 \%$ \\
Ginkgo Leaf & $33 \%$ & $0.31 \%$ & $0.41 \%$ \\
Olive Leaf & $30 \%$ & $0.15 \%$ & $0.33 \%$ \\
\hline
\end{tabular}

\section{Quantification of Elemental Composition in Dietary Samples}

After completing method validation for the UVPD procedure, the three different matrices listed in Table II were taken through the complete sample preparation stages (pre-digestion and UVPD), followed by ICP-MS and ICP-OES analysis. The major-to-ultratrace elements in the selected dietary supplement samples were determined by ICPOES ( $\mathrm{Na}, \mathrm{K}, \mathrm{Ca}, \mathrm{Mg}, \mathrm{Al}, \mathrm{Fe}, \mathrm{Mn}, \mathrm{Cu}$, $\mathrm{Zn}, \mathrm{P}$, and $\mathrm{Si}$ ) and ICP-MS (Cr, Mn, Co, Ni, Cu, Zn, As, Se, Sr, Cd, Cs,
Mo, $\mathrm{Hg}, \mathrm{Tl}, \mathrm{Pb}$, and $\mathrm{Bi}$ ) after UV photolysis digestion. As described in an earlier section, the analytical figures of merit for the ICP-OES and ICP-MS measurements, as well as the analytical reliabilities of the present method for sample digestion, were evaluated by comparing the results obtained by microwaveassisted digestion.

The concentrations of the 25 elements determined by both ICPOES and ICP-MS from each of the dietary supplements are collectively listed in Tables V-VIII for comparison and represent the mean of three replicate analyses. As seen from these tables, good agreement was found between the results obtained by UVPD and microwave- 
assisted digestion. Average recoveries for many metal concen- trations were found to be in the 95 to $103 \%$ range. Good accordance was observed between the values for $\mathrm{Zn}, \mathrm{Mn}$, and $\mathrm{Cu}$, obtained by both procedures and determined by both ICP-MS and ICP-OES.

However, ICP-MS allowed more elements to be measured, such as $\mathrm{Cr}$, $\mathrm{Ni}, \mathrm{Co}, \mathrm{Ni}, \mathrm{Se}, \mathrm{Sr}, \mathrm{Cd}, \mathrm{Cs}, \mathrm{Hg}, \mathrm{Tl}$, $\mathrm{Pb}$, and $\mathrm{Bi}$, which are not observable by ICP-OES due to sensitivity limitation.

The results given are for total elemental concentrations; no chemical speciation was performed. It is important to emphasize that toxicity is often dependent on individual chemical species of an element. From these results it was also observed that all of the tested dietary samples contain significant amounts of elements (major to ultratrace) with a wide variability. Among them, the highest concentration measured was $12,600 \mu \mathrm{g} \mathrm{g}^{-1}$ for potassium in turmeric supreme phytocaps; the lowest concentration was $<0.1 \mu \mathrm{g} \mathrm{g}^{-1}$ for the following elements in all of the samples: Co, Mo, $\mathrm{Cs}, \mathrm{Se}, \mathrm{Tl}, \mathrm{Hg}$, and $\mathrm{Bi}$.

\section{Essential and Other Elements}

The elements found in highest concentrations among all of the supplements tested were $\mathrm{Na}$ (7-6417 $\left.\mu \mathrm{g} \mathrm{g}^{-1}\right), \mathrm{Mg}\left(65-623 \mu \mathrm{g} \mathrm{g}^{-1}\right)$, $\mathrm{Ca}\left(25-470 \mu \mathrm{g} \mathrm{g}^{-1}\right)$, and $\mathrm{K}(100-$ $12,600 \mu \mathrm{g} \mathrm{g}^{-1}$ ) whose ingestion at recommended dosages would range from nanograms to milligrams per day. Castro et al. (14) reported the presence of $\mathrm{Na}$ and $\mathrm{Ca}$ in various glycerin-based products and ethanolic tinctures of botanical products in the range of 3-6750 $\mu \mathrm{g} \mathrm{g}^{-1}$ and 5-1900 $\mu \mathrm{g} \mathrm{g}^{-1}$, respectively.

The Fe content in the supplements ranged from 0.2 to $70 \mu \mathrm{g} \mathrm{g}^{-1}$. The highest concentration $\left(\sim 10 \mu \mathrm{g} \mathrm{g}^{-1}\right)$ was found in the turmeric supreme phytocap supplement and the low- est $\left(0.2 \mu \mathrm{g} \mathrm{g}^{-1}\right)$ determined was in the gingko leaf (alcohol-free) sample. Iron concentration levels ranging from 1.2 to $54 \mu \mathrm{g} \mathrm{g}^{-1}$ were reported by Castro et al. (14) in various glycerin-based and ethanolic tinctures of botanical products. The Al concentration (a toxic element) in the herbs varied between $0.5 \mu \mathrm{g} \mathrm{g}^{-1}$ (alcohol-free ginkgo leaf) and $13 \mu \mathrm{g} \mathrm{g}^{-1}$ (green tea ethanolic extract).

The Mn concentrations varied over a wide range from 0.4 to $33 \mu \mathrm{g} \mathrm{g}^{-1}$. The ginkgo phytocap supplement contained the lowest concentration of $\mathrm{Mn}\left(<0.4 \mu \mathrm{g} \mathrm{g}^{-1}\right)$, whereas the highest concentration was found in the ethanolic extract of the green tea sample.

The $\mathrm{Cu}$ and $\mathrm{Zn}$ concentrations in the dietary samples indicated similar maximum and minimum levels. However, the $\mathrm{Cu}$ levels in all of the herbs $\left(0.5 \mu \mathrm{g} \mathrm{g}^{-1}\right)$ were higher than the $\mathrm{Zn}$ levels $\left(2-13 \mu \mathrm{g} \mathrm{g}^{-1}\right)$. The highest $\mathrm{Cu}$ and $\mathrm{Mn}$ levels were measured in the green tea extract, whereas the lowest concentrations were determined in the gingko leaf and daily bitters, respectively.

The minimun $\mathrm{Cr}$ and $\mathrm{Ni}$ concentrations in the supplements were both $0.12 \mu \mathrm{g} \mathrm{g}^{-1}$, while the maximum $\mathrm{Cr}$ concentration was $0.68 \mu \mathrm{g} \mathrm{g}^{-1}$ and the maximum $\mathrm{Ni}$ concentration was $2.4 \mu \mathrm{g} \mathrm{g}^{-1}$.

The values obtained for Co, Cs, Mo, Tl, and Bi were at sub-ppb levels $\left(<0.1 \mu \mathrm{g} \mathrm{g}^{-1}\right)$. Of the 20 supplements tested, the six that contained low concentrations of both major and trace metals (nicotine relief, bronchial wellness, olive leaf extract, ginkgo phytocap, daily bitters) were mostly single-ingredient supplements. Interestingly, some of the dietary supplements, including green tea extract, Kava Kava root phytocap, and turmeric supreme phytocap, had higher concentrations of many of these metals.

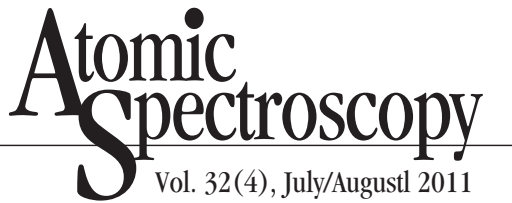

\section{Heavy Metals}

Heavy metals, including As, Cd, $\mathrm{Hg}$, and $\mathrm{Pb}$, are of primary concern due to their toxicity and potential to be present due to indiscriminate use of herbicides, pesticides, and mycotoxins, or because they may be occasionally used as ingredients in dietary supplements (15). Earlier studies on the determination of these elements in dietary supplements indicated that relatively high levels may be found. From Tables $\mathrm{V}$-XI, it can be seen that for most of the analyzed supplements, the concentration levels of As, Cd, and $\mathrm{Hg}$ were found to be significantly low ( $<50 \mathrm{ng} \mathrm{g}^{-1},<10 \mathrm{ng} \mathrm{g}^{-1}$, and $<50 \mathrm{ng} \mathrm{g}^{-1}$, respectively), except for the bladder wrack sample in which the As concentration was about $8 \mu \mathrm{g} \mathrm{g}^{-1}$. Two of the supplements (ginger extract, turmeric supreme extract) showed as much as $300 \mathrm{ng} \mathrm{g}^{-1}$ of $\mathrm{Pb}$. Therefore, the expected intake levels may not lead to any health risk. This assessment is predicted based on the assumption that all of these elements exist in their inorganic form. The degree of potential concern is dependent on the chemical form in which they are present in the sample.

In the studies carried out by Castro et al. (14), the toxic metals As, $\mathrm{Cd}, \mathrm{Hg}$, and $\mathrm{Pb}$ were not detected in any of the glycerin-based samples or in the ethanolic tinctures, possibly due to the sensitivity limitation of ICP-OES. Dolan et al. (16) determined $\mathrm{As}, \mathrm{Cd}, \mathrm{Hg}$, and $\mathrm{Pb}$ concentrations in 95 dietary supplements and NIST reference materials using microwave digestion and high resolution ICP-MS. The concentration ranges reported were as follows: As <5-3770 $\mathrm{ng} \mathrm{g}^{-1}$; Cd $<10-368 \mathrm{ng} \mathrm{g}^{-1}$, $\mathrm{Hg}<80-16800 \mathrm{ng} \mathrm{g}^{-1}$, and $\mathrm{Pb}$ $<20-48600 \mathrm{ng} \mathrm{g}^{-1}$. 
TABLE V

Elemental Composition of Ethanolic Extracts of Dietary Supplements $\left(\mu \mathrm{g} \mathrm{g}^{-1}\right)$

\begin{tabular}{|c|c|c|c|c|c|c|c|c|}
\hline \multirow[t]{3}{*}{ Element } & \multicolumn{4}{|c|}{ Bladder Wrack Fronds } & \multicolumn{4}{|c|}{ Green Tea } \\
\hline & \multicolumn{2}{|c|}{ UV Digestion } & \multicolumn{2}{|c|}{ MW Digestion } & \multicolumn{2}{|c|}{ UV Digestion } & \multicolumn{2}{|c|}{ MW Digestion } \\
\hline & ICP-MS & ICP-OES & ICP-MS & ICP-OES & ICP-MS & ICP-OES & ICP-MS & ICP-OES \\
\hline $\mathrm{Cr}$ & 0.31 & - & 0.36 & - & 0.34 & - & 0.31 & \\
\hline $\mathrm{Mn}$ & 5.00 & 5.40 & 5.30 & 5.20 & 31.60 & 31.50 & 31.20 & 33.20 \\
\hline $\mathrm{Ni}$ & 0.69 & - & 0.66 & - & 2.80 & 2.90 & 2.40 & 2.60 \\
\hline Co & 0.05 & - & 0.06 & - & 0.12 & - & 0.11 & - \\
\hline $\mathrm{Cu}$ & 0.73 & 0.76 & 0.73 & 0.74 & 4.60 & 4.70 & 4.80 & 4.50 \\
\hline $\mathrm{Zn}$ & 5.60 & 5.39 & 5.80 & 5.50 & 12.70 & 12.30 & 12.20 & 12.60 \\
\hline As & 8.40 & 8.59 & 8.40 & 9.03 & 0.05 & & 0.05 & - \\
\hline $\mathrm{Se}$ & 0.35 & - & 0.40 & - & 0.06 & - & 0.07 & - \\
\hline Mo & 0.01 & - & 0.01 & - & 0.01 & - & 0.02 & - \\
\hline Cd & 0.18 & - & 0.06 & - & 0.08 & - & 0.06 & \\
\hline Cs & 0.01 & - & 0.01 & - & 0.02 & - & 0.02 & - \\
\hline $\mathrm{Ba}$ & 0.41 & - & 0.39 & - & 0.28 & - & 0.25 & - \\
\hline Hg & 0.02 & - & 0.03 & - & 0.01 & - & 0.05 & - \\
\hline $\mathrm{Tl}$ & 0.02 & - & 0.02 & - & 0.02 & - & 0.02 & - \\
\hline $\mathbf{P b}$ & 0.03 & - & 0.03 & - & 0.13 & - & 0.11 & - \\
\hline $\mathrm{Bi}$ & 0.01 & - & 0.01 & - & 0.01 & - & 0.01 & \\
\hline $\mathrm{Al}$ & - & 1.40 & - & 1.40 & - & 12.80 & - & 12.20 \\
\hline $\mathrm{Fe}$ & - & 1.70 & - & 1.70 & - & 2.80 & - & 2.90 \\
\hline $\mathrm{Na}$ & - & 6417 & - & 6408 & - & 10 & - & 12 \\
\hline $\mathrm{K}$ & - & 5603 & - & 5604 & - & 5350 & - & 5330 \\
\hline $\mathrm{Ca}$ & - & 188 & - & 185 & - & 25 & - & 24 \\
\hline $\mathrm{Mg}$ & - & 471 & - & 457 & - & 218 & - & 221 \\
\hline $\mathrm{P}$ & - & 228 & - & 212 & - & 432 & - & 443 \\
\hline $\mathrm{Si}$ & - & 12.90 & - & 13.30 & - & 14.10 & - & 13.80 \\
\hline
\end{tabular}

Heavy elements are listed in bold font. 


\section{Atomic Spectroscopy \\ $\bigcirc$ Vol. 32(4), July/Augustl 2011}

TABLE VI

Elemental Composition of Liquid-based Phytocap Dietary Supplements $\left(\mu \mathrm{g} \mathrm{g}^{-1}\right)$

\begin{tabular}{|c|c|c|c|c|c|c|c|c|}
\hline \multirow[t]{3}{*}{ Element } & \multicolumn{4}{|c|}{ Kava Kava Root - Phytocap } & \multicolumn{4}{|c|}{ Tumeric Supreme - Phytocap } \\
\hline & \multicolumn{2}{|c|}{ UV Digestion } & \multicolumn{2}{|c|}{ MW Digestion } & \multicolumn{2}{|c|}{ UV Digestion } & \multicolumn{2}{|c|}{ MW Digestion } \\
\hline & ICP-MS & ICP-OES & ICP-MS & ICP-OES & ICP-MS & ICP-OES & ICP-MS & ICP-OES \\
\hline $\mathrm{Cr}$ & 0.25 & - & 0.29 & - & 0.35 & - & 0.37 & - \\
\hline Mn & 2.30 & 2.10 & 2.10 & 2.20 & 9.80 & 9.6 & 10.20 & 9.50 \\
\hline $\mathrm{Ni}$ & 0.36 & - & 0.35 & - & 0.41 & - & 0.35 & - \\
\hline Co & 0.06 & - & 0.06 & - & 0.06 & - & 0.05 & - \\
\hline $\mathrm{Cu}$ & 3.90 & 3.60 & 3.90 & 3.70 & 1.60 & 1.4 & 1.50 & 1.60 \\
\hline $\mathrm{Zn}$ & 8.20 & 7.90 & 7.60 & 8.10 & 4.00 & 3.8 & 4.10 & 4.00 \\
\hline As & 0.03 & - & 0.04 & - & 0.04 & - & 0.04 & - \\
\hline Se & 0.08 & - & 0.09 & - & 0.03 & - & 0.04 & - \\
\hline Mo & 0.04 & - & 0.03 & - & 0.02 & - & 0.02 & - \\
\hline Cd & 0.02 & - & 0.01 & - & 0.02 & - & 0.01 & - \\
\hline Cs & 0.03 & - & 0.03 & - & 0.03 & - & 0.03 & - \\
\hline $\mathrm{Ba}$ & 0.51 & - & 0.51 & - & 0.12 & - & 0.14 & - \\
\hline $\mathbf{H g}$ & 0.01 & - & 0.01 & - & 0.01 & - & 0.01 & - \\
\hline $\mathrm{Tl}$ & 0.02 & - & 0.02 & - & 0.02 & - & 0.02 & - \\
\hline $\mathbf{P b}$ & 0.21 & 0.24 & 0.23 & 0.21 & 0.26 & 0.25 & 0.24 & 0.27 \\
\hline $\mathrm{Bi}$ & 0.01 & - & 0.01 & - & 0.02 & - & 0.02 & - \\
\hline $\mathrm{Al}$ & - & 9.60 & - & 9.70 & - & 11.60 & - & 11.30 \\
\hline $\mathrm{Fe}$ & - & 9.10 & - & 9.00 & - & 24 & - & 23 \\
\hline $\mathrm{Na}$ & - & 212 & - & 209 & - & 96 & - & 95 \\
\hline K & - & 8933 & - & 8802 & - & 12608 & - & 12616 \\
\hline $\mathrm{Ca}$ & - & 290 & - & 291 & - & 270 & - & 265 \\
\hline $\mathrm{Mg}$ & - & 390 & - & 387 & - & 445 & - & 440 \\
\hline $\mathrm{P}$ & - & 2822 & - & 2890 & - & 3438 & - & 3509 \\
\hline $\mathrm{Si}$ & - & 68 & - & 65 & - & 73 & - & 75 \\
\hline
\end{tabular}

Heavy elements are listed in bold font. 
TABLE VII

Elemental Composition of Dietary Supplements $\left(\mu \mathrm{g} \mathrm{g}^{-1}\right)$

\begin{tabular}{|c|c|c|c|c|c|c|c|c|}
\hline \multirow[t]{3}{*}{ Element } & \multicolumn{4}{|c|}{$\begin{array}{c}\text { Nicotine Relief } \\
(60-60 \% \text { pure grain alcohol })\end{array}$} & \multicolumn{4}{|c|}{ Bronchial Wellness (Syrup) } \\
\hline & \multicolumn{2}{|c|}{ UV Digestion } & \multicolumn{2}{|c|}{ MW Digestion } & \multicolumn{2}{|c|}{ UV Digestion } & \multicolumn{2}{|c|}{ MW Digestion } \\
\hline & ICP-MS & ICP-OES & ICP-MS & ICP-OES & ICP-MS & ICP-OES & ICP-MS & ICP-OES \\
\hline $\mathrm{Cr}$ & 0.23 & - & 0.21 & & 0.12 & - & 0.13 & - \\
\hline $\mathrm{Mn}$ & 1.60 & 1.70 & 1.70 & 1.6 & 1.70 & 1.40 & 1.50 & 1.60 \\
\hline $\mathrm{Ni}$ & 0.35 & - & 0.37 & - & 0.32 & - & 0.29 & - \\
\hline Co & 0.04 & - & 0.04 & - & 0.03 & - & 0.03 & - \\
\hline $\mathrm{Cu}$ & 0.72 & 0.68 & 0.66 & 0.70 & 0.97 & 0.92 & 0.99 & 0.95 \\
\hline $\mathrm{Zn}$ & 5.20 & 5.10 & 5.00 & 5.10 & 1.90 & 1.60 & 1.70 & 1.80 \\
\hline As & 0.03 & - & 0.02 & - & 0.04 & - & 0.04 & - \\
\hline $\mathrm{Se}$ & 0.04 & - & 0.05 & - & 0.09 & - & 0.11 & - \\
\hline Mo & 0.02 & - & 0.01 & - & 0.04 & - & 0.04 & - \\
\hline Cd & 0.01 & - & 0.01 & - & 0.01 & - & 0.01 & - \\
\hline Cs & 0.01 & - & 0.02 & - & 0.02 & - & 0.02 & - \\
\hline $\mathrm{Ba}$ & 0.08 & - & 0.07 & - & 0.05 & - & 0.05 & - \\
\hline Hg & 0.07 & - & 0.07 & - & 0.05 & - & 0.05 & - \\
\hline $\mathrm{Tl}$ & 0.02 & - & 0.02 & - & 0.03 & - & 0.04 & - \\
\hline $\mathbf{P b}$ & 0.01 & & 0.01 & & 0.03 & & 0.03 & - \\
\hline $\mathrm{Bi}$ & 0.01 & - & 0.02 & - & 0.01 & - & 0.01 & - \\
\hline $\mathrm{Al}$ & - & 0.91 & - & 0.87 & - & 0.75 & - & 0.81 \\
\hline $\mathrm{Fe}$ & - & 1.90 & - & 2.10 & - & 1.2 & - & 1.10 \\
\hline $\mathrm{Na}$ & - & 92 & - & 91 & - & 61 & - & 59 \\
\hline $\mathrm{K}$ & - & 2390 & - & 2362 & - & 1706 & - & 1697 \\
\hline $\mathrm{Ca}$ & - & 135 & - & 141 & - & 151 & - & 145 \\
\hline $\mathrm{Mg}$ & - & 430 & - & 425 & - & 81 & - & 78 \\
\hline $\mathrm{P}$ & - & 84 & - & 89 & - & 97 & - & 94 \\
\hline $\mathrm{Si}$ & - & 13 & - & 11.80 & - & 9.40 & - & 9.10 \\
\hline
\end{tabular}

Heavy elements are listed in bold font. 


\section{Atomic \\ Spectroscopy \\ 1 Vol. 32(4), July/Augustl 2011}

TABLE VIII

Elemental Composition of Alcohol-free Based Dietary Supplements $\left(\mu \mathrm{g} \mathrm{g}^{-1}\right)$

\begin{tabular}{|c|c|c|c|c|c|c|c|c|}
\hline \multirow[t]{3}{*}{ Element } & \multicolumn{4}{|c|}{ Daily Bitters (alcohol-free) } & \multicolumn{4}{|c|}{ Ginkgo Leaf (alcohol-free) } \\
\hline & \multicolumn{2}{|c|}{ UV Digestion } & \multicolumn{2}{|c|}{ MW Digestion } & \multicolumn{2}{|c|}{ UV Digestion } & \multicolumn{2}{|c|}{ MW Digestion } \\
\hline & ICP-MS & ICP-OES & ICP-MS & ICP-OES & ICP-MS & ICP-OES & ICP-MS & ICP-OES \\
\hline $\mathrm{Cr}$ & 0.16 & 0.18 & 0.20 & 0.19 & 0.20 & - & 0.19 & - \\
\hline Mn & 2.50 & 2.30 & 2.70 & 2.40 & 1.70 & - & 0.22 & 0.19 \\
\hline $\mathrm{Ni}$ & 0.42 & - & 0.38 & - & 0.34 & - & 0.38 & - \\
\hline Co & 0.02 & - & 0.02 & - & 0.04 & - & 0.04 & - \\
\hline $\mathrm{Cu}$ & 1.90 & 1.60 & 1.70 & 1.80 & 0.55 & - & 0.49 & - \\
\hline $\mathrm{Zn}$ & 2.40 & 2.30 & 2.10 & 2.30 & 4.20 & 4.10 & 4.10 & 4.20 \\
\hline As & 0.03 & - & 0.02 & - & 0.03 & - & 0.04 & - \\
\hline $\mathrm{Se}$ & 0.14 & - & 0.12 & - & 0.05 & - & 0.05 & - \\
\hline Mo & 0.01 & - & 0.02 & - & 0.02 & - & 0.0 & - \\
\hline Cd & 0.01 & - & 0.01 & - & 0.01 & - & 0.01 & - \\
\hline Cs & 0.01 & - & 0.01 & - & 0.02 & - & 0.02 & - \\
\hline $\mathrm{Ba}$ & 0.51 & - & 0.52 & - & 0.29 & - & 0.30 & - \\
\hline Hg & 0.04 & - & 0.03 & - & 0.01 & - & 0.02 & - \\
\hline $\mathrm{Tl}$ & 0.02 & - & 0.02 & - & 0.03 & - & 0.03 & - \\
\hline $\mathbf{P b}$ & 0.03 & - & 0.03 & - & 0.04 & - & 0.03 & - \\
\hline $\mathrm{Bi}$ & 0.01 & - & 0.01 & - & 0.03 & - & 0.03 & - \\
\hline $\mathrm{Al}$ & - & 1.10 & - & 1.20 & - & 0.50 & - & 0.46 \\
\hline $\mathrm{Fe}$ & - & 1.20 & - & 1.20 & - & 0.19 & - & 0.20 \\
\hline $\mathrm{Na}$ & - & 95 & - & 92 & - & 6.90 & - & 6.70 \\
\hline $\mathrm{K}$ & - & 1987 & - & 1980 & - & 1938 & - & 1952 \\
\hline $\mathrm{Ca}$ & - & 87 & - & 87 & - & 77 & - & 76 \\
\hline $\mathrm{Mg}$ & - & 102 & - & 105 & - & 340 & - & 335 \\
\hline $\mathrm{P}$ & - & 146 & - & 140 & - & 330 & - & 325 \\
\hline $\mathrm{Si}$ & - & 14 & - & 15 & - & 22 & - & 23 \\
\hline
\end{tabular}

Heavy elements are listed in bold font. 
TABLE IX

Elemental Composition of Dietary Supplements After UVPD $\left(\mu \mathrm{g} \mathrm{g}^{-1}\right)$

\begin{tabular}{|c|c|c|c|c|c|c|c|c|}
\hline \multirow[t]{2}{*}{ Element } & \multicolumn{2}{|c|}{ Echinacea Supreme } & \multicolumn{2}{|c|}{ Milk Thistle Extract } & \multicolumn{2}{|c|}{ Olive Leaf Extract } & \multicolumn{2}{|c|}{ Black Elderberry-Phytocap } \\
\hline & ICP-MS & ICP-OES & ICP-MS & ICP-OES & ICP-MS & ICP-OES & ICP-MS & ICP-OES \\
\hline $\mathrm{Cr}$ & 0.24 & - & 0.28 & - & 0.31 & - & 0.04 & - \\
\hline Mn & 0.59 & 0.57 & 0.96 & 0.86 & 1.70 & 2.10 & 8.80 & 8.70 \\
\hline $\mathrm{Ni}$ & 0.51 & - & 1.23 & 1.25 & 0.12 & - & 0.37 & - \\
\hline $\mathrm{Co}$ & 0.05 & - & 0.07 & & 0.08 & - & 0.02 & - \\
\hline $\mathrm{Cu}$ & 1.40 & 1.30 & 7.90 & 7.80 & 2.90 & 2.20 & 2.80 & 2.60 \\
\hline $\mathrm{Zn}$ & 6.90 & 6.60 & 7.30 & 7.50 & 3.20 & 2.50 & 12.90 & 12.70 \\
\hline As & 0.05 & - & 0.06 & - & 0.06 & - & 0.05 & - \\
\hline $\mathrm{Se}$ & 0.24 & - & 0.02 & - & 0.02 & - & 0.23 & - \\
\hline Mo & 0.02 & - & 0.02 & - & 0.02 & - & 0.02 & - \\
\hline Cd & 0.09 & - & 0.33 & - & 0.33 & - & 0.01 & - \\
\hline Cs & 0.05 & - & 0.04 & - & 0.02 & - & 0.02 & - \\
\hline $\mathrm{Ba}$ & 0.03 & - & 0.01 & - & 0.19 & - & 0.33 & - \\
\hline Hg & 0.02 & - & 0.03 & - & 0.02 & - & 0.05 & - \\
\hline $\mathrm{Tl}$ & 0.02 & - & 0.12 & - & 0.08 & - & 0.05 & - \\
\hline $\mathbf{P b}$ & 0.11 & - & 0.02 & - & 0.02 & - & 0.15 & - \\
\hline $\mathrm{Bi}$ & 0.02 & - & 0.02 & - & 0.02 & - & - & - \\
\hline $\mathrm{Al}$ & - & 0.38 & - & 1.80 & - & 1.90 & - & 4.30 \\
\hline $\mathrm{Fe}$ & - & 1.05 & - & 8.10 & - & 3.30 & - & 8.90 \\
\hline $\mathrm{Na}$ & - & 70 & - & 23 & - & 244 & - & 132 \\
\hline $\mathrm{K}$ & - & 6589 & - & 2684 & - & 2013 & - & 1695 \\
\hline $\mathrm{Ca}$ & - & 176 & - & 42 & - & 220 & - & 348 \\
\hline $\mathrm{Mg}$ & - & 312 & - & 66 & - & 476 & - & 720 \\
\hline $\mathrm{P}$ & - & 197 & - & 255 & - & 324 & - & 1890 \\
\hline $\mathrm{Si}$ & - & 29.50 & - & 14.50 & - & 21 & - & 52 \\
\hline
\end{tabular}

Heavy elements are listed in bold font. 


\section{Atomic Spectroscopy \\ 1 Vol. 32(4), July/Augustl 2011}

TABLE $X$

Elemental Composition of Dietary Supplements After UVPD $\left(\mu \mathrm{g} \mathrm{g}^{-1}\right)$

\begin{tabular}{|c|c|c|c|c|c|c|c|c|}
\hline \multirow[t]{2}{*}{ Element } & \multicolumn{2}{|c|}{$\begin{array}{l}\text { Echinacea Supreme } \\
\text { Phytocap }\end{array}$} & \multicolumn{2}{|c|}{$\begin{array}{l}\text { Ginkgo } \\
\text { Phytocap }\end{array}$} & \multicolumn{2}{|c|}{$\begin{array}{l}\text { Green Tea } \\
\text { Phytocap }\end{array}$} & \multicolumn{2}{|c|}{$\begin{array}{l}\text { Ginger Supreme } \\
\text { Phytocap }\end{array}$} \\
\hline & ICP-MS & ICP-OES & ICP-MS & ICP-OES & ICP-MS & ICP-OES & ICP-MS & ICP-OES \\
\hline $\mathrm{Cr}$ & 0.26 & - & 0.18 & - & 0.31 & - & 0.12 & - \\
\hline Mn & 1.50 & 1.50 & 0.39 & 0.35 & 8.30 & 8.20 & 9.30 & 8.90 \\
\hline $\mathrm{Ni}$ & 0.34 & - & 0.21 & - & 2.10 & - & 0.35 & - \\
\hline Co & 0.01 & - & 0.01 & - & 0.01 & - & 0.06 & - \\
\hline $\mathrm{Cu}$ & 4.40 & 4.30 & 0.80 & 0.90 & 3.30 & 3.30 & 4.10 & 3.90 \\
\hline $\mathrm{Zn}$ & 5.10 & 5.10 & 1.70 & 1.30 & 7.40 & 7.20 & 4.80 & 4.90 \\
\hline As & 0.02 & - & 0.05 & - & 0.02 & - & 0.05 & - \\
\hline $\mathrm{Se}$ & 0.13 & - & 0.15 & - & 0.02 & - & 0.09 & - \\
\hline Mo & 0.02 & & 0.01 & - & 0.03 & - & 0.02 & - \\
\hline Cd & 0.01 & -- & 0.01 & - & 0.01 & - & 0.01 & - \\
\hline Cs & 0.03 & - & 0.05 & - & 0.19 & - & 0.01 & - \\
\hline $\mathrm{Ba}$ & 0.18 & - & 0.26 & - & 0.21 & - & 0.11 & - \\
\hline Hg & 0.01 & - & 0.04 & - & 0.03 & - & 0.03 & - \\
\hline $\mathrm{Tl}$ & 0.01 & - & 0.02 & - & 0.02 & - & 0.01 & - \\
\hline $\mathbf{P b}$ & 0.02 & - & 0.07 & - & 0.05 & - & 0.02 & - \\
\hline $\mathrm{Bi}$ & 0.01 & - & 0.01 & - & 0.02 & - & 0.64 & - \\
\hline $\mathrm{Al}$ & - & 2.60 & - & 0.35 & - & 8.70 & - & 9.05 \\
\hline $\mathrm{Fe}$ & - & 3.90 & - & 0.43 & - & 5.60 & - & 7.20 \\
\hline $\mathrm{Na}$ & - & 168 & - & 130 & - & 190 & - & 133 \\
\hline K & - & 8650 & - & 3560 & - & 2475 & - & 9307 \\
\hline $\mathrm{Ca}$ & - & 470 & - & 87 & - & 115 & - & 98 \\
\hline $\mathrm{Mg}$ & - & 620 & - & 723 & - & 93 & - & 221 \\
\hline $\mathrm{P}$ & - & 435 & - & 320 & - & 245 & - & 1102 \\
\hline $\mathrm{Si}$ & - & 36.50 & - & 29 & - & 15.50 & - & 37 \\
\hline
\end{tabular}

Heavy elements are listed in bold font. 
TABLE XI

Elemental Composition of Dietary Supplements After UVPD $\left(\mu \mathrm{g} \mathrm{g}^{-1}\right)$

\begin{tabular}{|c|c|c|c|c|c|c|c|c|}
\hline \multirow[t]{2}{*}{ Element } & \multicolumn{2}{|c|}{$\begin{array}{l}\text { Antioxidant } \\
\text { Phytocap }\end{array}$} & \multicolumn{2}{|c|}{$\begin{array}{l}\text { Olive Leaf } \\
\text { Phytocap }\end{array}$} & \multicolumn{2}{|c|}{$\begin{array}{l}\text { Hawthorn } \\
\text { Solid Extract }\end{array}$} & \multicolumn{2}{|c|}{$\begin{array}{c}\text { Black Elderberry } \\
\text { Syrup }\end{array}$} \\
\hline & ICP-MS & ICP-OES & ICP-MS & ICP-OES & ICP-MS & ICP-OES & ICP-MS & ICP-OES \\
\hline $\mathrm{Cr}$ & 0.19 & - & 0.23 & - & 0.23 & - & 0.12 & - \\
\hline $\mathrm{Mn}$ & 3.90 & 4.02 & 2.40 & 2.90 & 0.87 & 0.84 & 9.80 & 9.60 \\
\hline $\mathrm{Ni}$ & 2.20 & 2.10 & 1.20 & 1.40 & 0.67 & - & 0.32 & - \\
\hline $\mathrm{Co}$ & 0.06 & - & 0.03 & - & 0.05 & - & 0.03 & - \\
\hline $\mathrm{Cu}$ & 3.90 & 3.60 & 2.30 & 2.10 & 2.90 & 3.10 & 5.90 & 6.00 \\
\hline $\mathrm{Zn}$ & 3.70 & 3.60 & 3.90 & 3.30 & 2.07 & 2.05 & 6.80 & 6.80 \\
\hline As & 0.08 & - & 0.03 & - & 0.03 & - & 0.03 & - \\
\hline Se & 0.22 & - & 0.06 & - & 0.06 & - & 0.09 & - \\
\hline Mo & 0.01 & - & 0.02 & - & 0.03 & - & 0.01 & - \\
\hline Cd & 0.02 & - & 0.02 & - & 0.02 & - & 0.01 & - \\
\hline Cs & 0.01 & - & 0.02 & - & 0.23 & - & 0.01 & - \\
\hline $\mathrm{Ba}$ & 0.01 & - & 0.01 & - & 0.19 & - & 0.05 & - \\
\hline Hg & 0.02 & - & 0.02 & - & 0.01 & - & 0.01 & - \\
\hline $\mathrm{Tl}$ & 0.01 & - & 0.02 & - & 0.02 & - & 0.02 & - \\
\hline $\mathbf{P b}$ & 0.16 & - & 0.15 & - & 0.04 & - & 0.04 & - \\
\hline $\mathrm{Bi}$ & 0.02 & - & 0.01 & - & 0.01 & - & 0.01 & - \\
\hline $\mathrm{Al}$ & - & - & - & 1.80 & - & 0.87 & - & 0.75 \\
\hline $\mathrm{Fe}$ & - & 4.70 & - & 3.20 & - & 0.51 & - & 70 \\
\hline $\mathrm{Na}$ & - & 96 & - & 450 & - & 16 & - & 132 \\
\hline $\mathrm{K}$ & - & 1850 & - & 4810 & - & 4550 & - & 1695 \\
\hline $\mathrm{Ca}$ & - & 160 & - & 460 & - & 175 & - & 350 \\
\hline Mg & - & 155 & - & 640 & - & 355 & - & 718 \\
\hline $\mathrm{P}$ & - & 175 & - & 116 & - & 650 & - & 589 \\
\hline $\mathrm{Si}$ & - & 24 & - & 13.50 & - & 17 & - & 33 \\
\hline
\end{tabular}

Heavy elements are listed in bold font. 


\section{Sample Throughput and Reagent Consumption}

In the case of the UVPD procedure, the longest time requirement for digestion was about 40 minutes ( $<5$ minutes for pre-digestion), making it possible to prepare as many as 100 to 120 samples per an 8-hour working day. Microwaveassisted extraction requires $60 \mathrm{~min}$ utes for digestion, but the time required for the reactor to cool before opening is about 90 to 120 minutes (at room temperature) which limits the number of samples that can be prepared in a day.

The consumption of reagents is reduced with UVPD versus microwave sample preparation. The UVPD procedure requires $5 \mathrm{~mL}$ of $20 \% \mathrm{HNO}_{3}$, which is sufficient to obtain clear solutions and recover most of the analytes from dietary samples. But in the case of microwave-assisted extraction, up to $10 \mathrm{~mL}$ of concentrated $\mathrm{HNO}_{3}$ is required for digestion. The whole process of UVPD is faster and simpler since the reduced number of analytical steps involved minimizes contamination risks.

\section{CONCLUSION}

The UV photolysis digestion (UVPD) procedure developed in the present study offers an effective method of sample preparation for the multi-elemental determination (Na, K, Ca, Mg, Fe, P, Si, Al, Cr, Mn, $\mathrm{Cu}, \mathrm{Zn}, \mathrm{As}, \mathrm{Se}, \mathrm{Sr}, \mathrm{Tl}, \mathrm{Cd}, \mathrm{Mo}, \mathrm{Hg}$, $\mathrm{Pb}$, and $\mathrm{Bi}$ ) in a variety of liquidbased dietary supplements using ICP-MS and ICP-OES. This is reflected by the excellent recoveries obtained for all of the elements tested in the present study after the UVPD process by keeping acid concentration $\left(20 \% \mathrm{HNO}_{3}\right)$ and sample weight $(300 \mathrm{mg}$ ) constant. Recovery of the tested elements was obtained by the addition of aqueous standard solutions to the samples prior to the pre-digestion step and it was carried through every step of
UVPD. In addition, method validation was carried out by comparing the results from UVPD to a recently reported microwave-assisted digestion method. UVPD preparations were complete within 40 minutes with a 300-mg sample, a factor of at least 2 to 3 times faster than for the microwave-assisted digestion method. Further work is planned to examine the possibility of identifying the different chemical species (i.e., speciation) of arsenic present in bladder wrack samples for accurate toxicological assessment.

An overall precision of better than $8 \%$ was achieved for many elements in multiple digestions. A published closed microwave digestion method was used for validation purposes. These studies demonstrate that the proposed UVPD method is a simple, rapid (20-40 minutes, including pre-digestion time), and viable approach for the determination of various elements at major to ultratrace levels in a variety of dietary supplements for assessing their potential implications for health.

\section{ACKNOWLEDGMENTS}

The authors would like to thank Dr. J. Arunachalam, Head, CCCM, Dr. Sunil Jai Kumar, Head, Ultratrace Analysis Section of CCCM, for their constant support and encouragement. We thank GAIA Herbs, Brevard, NC, USA, for providing us the samples for this work. We also thank Ms. Sailaja Pandey for helping in the ICP-MS measurements and Ms. Ayushi for the TOC measurements.

Received April 5, 2011.

\section{REFERENCES}

1. World Health Organization (WHO) guidelines for assessing quality of herbal medicines with reference to contaminants and residues, World Health Organization, Geneva, Switzerland (2007).

2. E. Ernst, Clin. Pharmacol. and Therapeutics 70/6, 497 (2001).

3. E. Ernst, Trends Pharmacol. Sci. 23/3, 136 (2002).

4. G. B. van der Voet, A. Sarafanov, T. I. Todorov, J. A. Centeno, W. B. Jonas, J. A. Ives, and F. G. Mullick, Biol. Trace Elem. Res. 125, 1 (2008).

5. S. A. Jordan, D. G. Cunningham. and R. J. Marles, Toxicol. and Appl. Pharmacol. 243, 198 (2010).

6. F. Stickel, E. Patsenker. and D. Schuppan, Herbal Hepatoxicity, J. Hepatol. 49, 901 (2005).

7. A. A. Grippo, B. Hamilton, R. Hanningan. and B. J. Gurley, Am. J Health-Syst. Pharm. 63, 635 (2006).

8. M. V. Balarama Krishna, J. Castro, T. M. Brewer, and R. K. Marcus, J. Anal. At. Spectrom. 24, 199 (2009).

9. S. G. Capar, W. R. Mindak, and J. Cheng, Anal. Bioanal. Chem. 389, 159 (2007).

10. A. Arceusz, I. Redecka, and M. Wesolowski, Food Chem. 120, 52 (2010).

11. S. P. Dolan and S. G. Capar, J. Food Comp. Anal. 15, 593 (2002).

12. H. Matsuura, A. Hokura, F. Katsuki, A. Itoh, and Haraguchi, Anal. Sci. 17, 391 (2001).

13. A. Krejcova, D. Kahoun, T. Cernohorsky, and M. Pouzar, Food Chem. 98, 171 (2006).

14. J. Castro, Julia C. Spraul, and R. Kenneth Marcus, Anal. Methods 1, 188 (2009).

15. P. Raman, Lina C. Patino, and M. G. Nair, J. Agric. Food Chem. 52, 7822 (2004).

16. S. P. Dolan, D. A. Nortrup, P. M. Bolger, and S. G. Capar, J. Agric. Food Chem. 51, 1307 (2003.

17. R. Nageswara Rao and M.V.N. Kumar Talluri, J. Pharma. Biomed. Anal. 43, 1 (2007). 
18. U. Injang, P. Noyrod, W.

Siangproh, W. Dungchai, S.

Motomizu, and O. Chailapakul, Anal. Chim. Acta 668, 54 (2010).

19. Akbar Montaser and D.W. Golightly (Eds.), Inductively Coupled Plasmas in Analytical Atomic Spectrometry, 2nd Edition (1991).

20. J. S. Becker and N. Jakubowski, Chem. Soc. Rev. 38, 1969 (2009).

21. P. L. Buldini, L. Ricci, and J. L. Sharma, J. Chromatogr. A 975, 47 (2002).

22. M. d. G. A. Korn, E.S da Boa Morte, D. C. M. B. dos Santos, J. T. Castro, J. T. P. Barbosa, A. P. Teixeira, A. P. Fernandes, B. Welz, W. P. C. dos Santos, E. B. G. N. dos Santos, and M. Korn, Appl. Spectr. Rev. 43, 67 (2008).

23. J. L. Capelo-Martinez, P. XimenezEmbun, Y. Madrid, and C. Camara, Trends Anal. Chem. 23/4, 331 (2004).

24. F. A. J. Armstrong, P. M. Williams, and J. D. H. Strickland, Nature 211, 481 (1966).

25. P. L. Buldini, S. Cavalli, and A Mevoli, J. Chromatogr. A 739, 167 (1996).

26. J. Golimowski K and. Golimowska, Anal. Chim. Acta 325, 111 (1996).

27. D. Monticelli, G. Carugati, A. Castelletti, S. Tecchia, and C. Dosso, Microchem. J. 95, 158 (2010).

28. G. Philippeit and J. Angerer, J. Chromatogr. B, Biomed. Sci. Appl. 760, 237 (2001).

29. R. Manjusha, K. Dash, and D. Karunasagar, Food Chem. 105, 260 (2007). 